\title{
What leads to Employee Engagement in Pharmaceutical Sector of Pakistan?
}

\author{
Shiraz Ahmed ${ }^{1} \&$ Junaid Ansari*2 \\ 1,2Institute Of Business Management, Karachi, Pakistan
}

\begin{abstract}
Managers and HR professionals are always concerned with the engagement of employees at workplace. Using attitude theory this study aims to examine the connection between employee engagement with job fit, psychological climate, leadership style and affective commitment. A sample of 284 employees out of 365 participants was chosen from two pharmaceutical companies based in Karachi. SPSS was used to analyze the data and different statistical tool were applied. The results of the study showed that the independent variables, i.e. job fit, psychological climate, leadership style and affective commitment have a significant and positive influence on employee engagement. All the hypotheses were failed to reject. This study can help HR professionals in designing the strategy for retention and engagement. The results which are presented in this study can help organizations to identify the potential reasons for engagement which leads to high productivity and profitability.
\end{abstract}

Key words: Job fit, affective commitment, psychological climate, employee engagement, leadership style.

\section{Introduction}

Employee engagement is a vital and crucial factor to increase productivity and profitability. These days it has got considerable importance by the organization to lower the turnover rate (Lockwood, 2007); though, it has been discussed by the some researchers but there is still very shortage on the study of engagement, i.e. the drivers of engagement (Macey and Schneider, 2008). Actually, it is the obligation of HR practitioners to search the factors related to engagement which can be included in the strategy for retention and strategic planning. These days Employee engagement has become an issue at the CEO level (Saks and Gruman, 2011).

The research conducted by the Buckingham (1999) and Cartwright and Holmes (2006) showed that only $30 \%$ employees are engaged and the rest are not engaged and disengaged. The engaged employees were found to be more associated with the organization at cognitive and physical level (Crabtree, 2004). These employees usually didnt get absent from the work (Wagner and Harter, 2007) as compared to their colleagues, thus these employees save the profitability of the organization up to 86.5 million every year in terms of productivity (Gebauer et al., 2008; Sundaray, 2011). Additionally, involved operatives have been revealed as an important factor for

* Corresponding author.

Email: junaid.ansari@iobm.edu.pk 
less accidents when employees are performing work (Wagner and Harter, 2007). This study also highlights that the people who are physically, cognitively and affectionally engaged at the workplace brings more clients and provides customer satisfaction and also shares positive feelings and emotions with their colleagues. Earlier researches show that there is a gap on how to create employee engagement and its antecedents variable. This gap has guided this research to work in this area.

\subsection{Objectives}

Employee engagement is a vital and crucial factor to increase productivity and profitability. Additionally, employee engagement has been revealed as an important factor for less accidents when employees are performing work (Wagner and Harter, 2007). This discussion leads to formulate the following objectives on the research questions.

1. To determine influence of job fit on employee engagement

2. To determine influence of affective commitment on employee engagement

3. To determine influence of Leadership Style on employee engagement

4. To determine influence of Psychological climate on employee engagement

\subsection{Gaps and Contribution}

One of the elementary problems with these studies is the subject and the context. The previous researches were conducted in different countries, therefore generalizing their results is difficult. This research study was focused on the antecedents of employee engagement in the two pharmaceutical organizations located in Karachi only. Therefore the results cannot be generalized to whole of the country. The factors related to respondents social environment and backgrounds are not considered for this study.

\section{Literature Review}

Macey and Schneider (2008) investigated four specific variables, which include the classification of fit measure, its means of calculation, dimensions and its use as a benchmark for established measure of personorganization fit. The strongest relationship were found between fit and job criteria, which is subjective in nature. The study also indicated that value congruency and personality negatively affects employee work engagement. Recent study by Gallup indicated that Singaporean employers lose $\$ 30$ billion dollars and USA economy 3 trillion dollars every year. The study also highlighted that only less than $20 \%$ employees are engaged and the rest are not engaged and disengaged. The engaged employees out perform disengaged employees to 3:1, which means they are three times more profitable to disengaged ones. The cost of high disengagement is a serious concern for managers and organizations.

Zigarmi (2008) discussed the role of job attitude in measuring employee engagement. They critically examine the link between the job attitudes namely organizational commitment, job involvement, job satisfaction with employee engagement. Hypotheses based on the theoretical model were developed to illustrate the relationship among the variables discussed in the research. 
Numerous researchers instituted the empirical facts on whether employee engagement influences the level of change and creativity inside workplace (Chaudhary and Akhouri, 2019; Elwyn et al., 2017). The aftermath magnifies the act of operative employee involvement on creativity and change in the workplace. The aftermath counsel that involved operative is exhilarated in their obligations and tasks that make them to contemplate creatively and to go supplementary mile. The researchers, moreover discovered that a trustful work nature, job empowerment and a little sense of autonomy are not merely relevant in enhancing operative assurance but are additionally momentous in reassuring creativity and innovation.

\subsection{Employee Engagement}

Employee engagement is a vital and crucial factor to increase productivity and profitability. These days it has got considerable importance by the organization to lower the turnover rate (Huang et al., 2016); though, it has been discussed by the some researchers but there is still very shortage on the study of engagement, i.e. the drivers of engagement (Barik and Kochar, 2017).

\subsection{Job Fit}

Job fit characterized by Bui et al. (2017) demonstrated a connection of employee state of mind and conduct which is powerfully identified with employee engagement and duty. Those employees who feel strongly that they have great job fit result as experience professional comparing with their organization. The job fit gives energy to employees to set up a feeling of employee engagement at their work (Chen et al., 2014).

\subsection{Affective Commitment}

The affective commitment of employee is considered as an enthusiastic bond with organization and has been viewed as a huge determinant of duty and commitment. Those workers who are affectively dedicated tend to build their support in the organizations exercises (Rhoades et al., 2001). Affectively dedicated employees get a feeling of seriousness in their work (Kahn, 1990) and feel expressively and mentally secure to interface with work (Rhoades et al., 2001).

\subsection{Psychological Climate}

Harter et al. (2010) set up that these variables significantly identify with the understanding of employee's learning of work and affect the advancement of employee engagement. As per Kataria et al. (2019) a familiarity with security and openness with work got advanced in psychological climate and offer certainty to people in accomplishment of seriousness in their work parts Kahn (1990). The variables which influence an employee's attitude at work include job challenge or supportive manager results in positive employee engagement (Czarnowsky, 2008; Wagner and Harter, 2006).

\subsection{Leadership Style}

Leadership style refers to the moves a pioneer makes to propel subordinates and fulfill authoritative objectives through others. Leadership style is represented by the accompanying sorts of leadership practices: contingent reward, management by exception (passive and active), and 
laissez-faire. Contingent reward portrays the trading of resources that happens between a leader and his employee. The important aspect of transactional leadership style, sometimes portrayed as "non-leadership" is the laissez-faire style. This arrangement of practices alludes to the avoidance of leadership tasks, for example, setting objectives, observing performance, and coaching which contributes towards employee engagement (Breevaart et al., 2016).

\subsection{Job Fit and Employee Engagement}

Several Studies were conducted to understand relationship between job fit and employee engagement (Bui et al., 2017). One of the studies was conducted by Saks and Gruman (2011) suggested that job fit encourages the employees to be more involved in their jobs and have high employee engagement ultimately resulting in polishing the behaviors related to work. Employee engagement is the state of connection of an employee where he is engaged on a long term to an organization regardless of additional benefits. It is a state where employee is satisfied with job and is actually engaged on the work cognitively, physically and affectionally (Wagner and Harter, 2007). The people who are physically, emotionally and cognitively engaged come to work daily and their absenteeism is low as compared to others (Magee et al., 2017), they are consistently associated with the work at all levels.

\section{$\mathrm{H}_{1}$ : Job fit positively influences Employee engagement}

\subsection{Affective Commitment and Employee Engagement}

Affective commitment has been defined and explained by various researchers for example Albrecht and Marty (2020) believe there is a strong relationship between affective commitment and employee engagement. Another study was conducted by Rhoades et al. (2001) and they have found it that an affective bond that employees have with their organization leads to certain important factors such as employee engagement, dedication, loyalty, and satisfaction. Furthermore, affective commitment focused on emotional connection employees have with their work and level of emotive qualities of engagement.

According to Rhoades et al. (2001), there are certain antecedents which are necessary for determining connection between affective commitment and employee engagement. These factors include support from supervisor, empowerment, rewards and justice with consideration. Similarly, Rhoades et al. (2001) argued that certain outcome variables for example absenteeism, performance, and turnover also depict level of affective commitment. These qualities show how deeply committed the employees are towards their tasks dedicated to achieve organizational goals (Harter et al., 2003).

$\mathrm{H}_{2}$ : Affective commitment positively influences Employee engagement

\subsection{Psychological Climate and Employee Engagement}

There are a number of researches that explore the meaning of psychological climate and its significance to employee engagement (Paek et al., 2015). Psychological climate has been operationalized into several components. Brown and Leigh (1996) were inspired by Kahn (1990) original theory of engagement and believed that there is a strong link of psychological climate that an employee is in and the level of engagement he shows at work. O'Neill and Arendt (2008) tried to explain psychological climate through the eyes of employees, he elaborates that it 
is important to understand through the eyes of employees for example how he perceives meaningful work and psychological representations of structures, processes and events that occur in organization. In short Psychological climate helps in determining a framework to a particular organizations culture and research.

On the bases of the above literature review, following hypotheses was created:

$\mathrm{H}_{3}$ : Psychological climate positively influences Employee engagement

\subsection{Leadership style and Employee Engagement}

Numerous studies found the relationship of leadership with employee engagement (Busse and Regenberg, 2019). A research was conducted by Christian et al. (2011) argued that there is a relationship between Transformational Leadership and Employee Engagement. There is a medium size correlation between employee engagement and Transformational Leadership. Another research was conducted by three of the famous authors (Purvanova et al., 2006). They have elaborated on this link which clearly shows that employee perceptions on employee engagement and job importance is the one of the mediating factor between Employee Engagement and Transformational Leadership. Macey and Schneider (2008) have jointly worked and discussed on multi-dimensional nature of employee engagement. According to them, they say that Transformational Leadership has an impact on Employee Engagement.

Employee engagement is the state of connection of an employee where he is engaged on a long term to an organization regardless of additional benefits. It is a state where employee is satisfied with job and is actually engaged on the work cognitively, physically and affectionally (Wagner and Harter, 2007). The people who are physically, emotionally and cognitively engaged come to work daily and their absenteeism is low as compared to others (Magee et al., 2017), they are consistently associated with the work at all levels.

A research was conducted by Bernthal and Wellins (2006). They have extended the work of Judge et al. (2002) by doing analysis and explored their ideas that a leaders personality relates to transactional and transformational leadership and how that results in Employee engagement. The concept of extraversion has emerged as a significant predictor of all major factors of transformational leadership (idealized influence and inspirational motivation are all combined from a charismatic leadership component).

$\mathrm{H}_{4}$ : Leadership style positively influences Employee engagement

\subsection{Conceptual Framework}

On the premise of the above writing dialog, employee engagement has been found as a dependent variable and job fit, affective commitment, leadership style and psychological climate as an autonomous variable. On the backing of these variables, taking after reasonable edge work has been made and examination is done underneath.

In particular, if one species a broad behavioral criterion that describes the overlap among job performance, organizational citizenship behavior, and withdrawal (that is, lateness, absence, and turnover), then, accord- ing to attitude theory, a broad job attitude should predict this criterion very strongly.

In particular, if one species a broad behavioral criterion that describes the overlap among job performance, organizational citizenship behavior, and withdrawal (that is, lateness, absence, and turnover), then, accord- ing to attitude theory, a broad job attitude should predict this criterion very strongly In particular, if one postulates a behavioral criterion that describes employee 
engagement then, under the umbrella of attitude theory, employee engagement should predict by job attitudes.

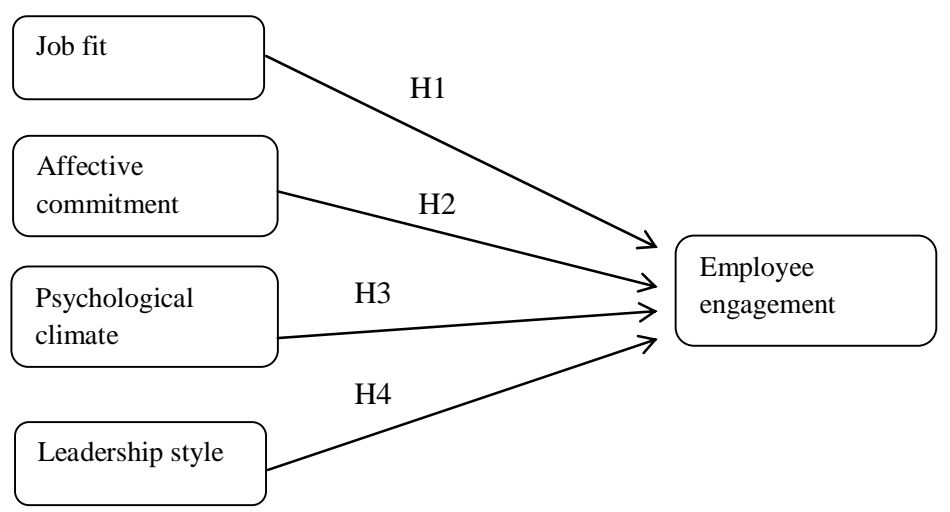

Figure 1: Conceptual Framework

\section{Methodology}

The research design is based on Quantitative approach. SPSS 18 was used to evaluate the hypotheses. Questionnaire was used to collect the responses. Different statistical tests were conducted to analyze the data. These statistical tests include reliability (Cronbachs Alpha), Exploratory Factor Analysis (EFA), Validity (Convergent \& Discriminant), correlation (Karl Pearson Bivariate Correlation), and regression analysis.

\subsection{Population and Sample}

Employees of pharmaceutical companies were selected as the population for this study and the total of this population was approximately more than 7000 employees. The sample size calculated through Raosoft (2004) for this study which was 365 participants. The total number of received questionnaire was 383 . All the respondents participated in this research were on voluntary basis. The response rate was $78 \%$. The sampling technique employed for this study is Convenience sampling (non-probability). It is simple, fair and reasonable to collect the data, select a sample, accomplish the result and generalize the results through this sampling technique. If arbitrary selection is done properly, the sample is therefore representative of the entire population Lund (2012). Three modified scales which were originally developed by May et al. (2004) are used to measure an individuals grade of employee engagement at work. This is a 17-item scale. The reliability of this scale in this study is $\alpha=.89$.

\subsection{Measurement \& Scale}

The Person-Organization Fit Scale Kasemsap (2013) is a 5-item scale where participants were evaluated on a 7-point Likert scale from 1 (strongly disagree) to 7 (strongly agree). Coefficient 
alpha for the Person-Organization Fit Scale in the present study was $\alpha=.92$. The instrument used for measuring Affective commitment was developed by Allen and Meyer (1996) and Meyer et al. (1990). The original Affective commitment scale is a 6-item scale. The reliability estimates between .74 and .88 .

\section{Results}

This section describes the demographic profiles and the statistical analysis conducted on the basis of the data collected from the respondents.

\subsection{Respondents Profile}

Demographics of the respondents selected for this study are discussed in Table 1 which includes the information regarding their age, income and education. It was noticed that majority of the respondents were male, and marital status of most of the respondents were single. It was also noticed that young employees were majority in numbers i.e. $44 \%$. The income of the majority people were found between 31 to 40 thousand PKR.

\subsection{Descriptive Statistics}

The normality of the data was ascertained through descriptive statistics which is summarized in Table 2. Results contain the mean, standard deviation, skewness, and kurtosis values. The acceptable range of Skewness and Kurtosis for satisfying the conditions of univariate normality is \pm 3.5 (Harlow, 2014)

Table 2 shows the descriptive statistics results. It can be seen that the values of lowest and highest skewenss are referred to Leadership Style (Mean $=4.799, \mathrm{SD}=1.066, \mathrm{SK}=-0.270$ ), and Employee Engagement (Mean $=4.757, \mathrm{SD}=0.873, \mathrm{SK}=-0.676$ ) respectively. The Kurtosis for Psychological climate is positive while all the other items have a negative kurtosis. The values of lowest and the highest kurtosis are referred to Affective Commitment (Mean $=4.800, \mathrm{SD}=$ $0.9446, \mathrm{KT}=-.125)$ and Employee Engagement $(\mathrm{Mean}=4.757, \mathrm{SD}=0.873, \mathrm{KT}=-0.568)$ respectively.

\subsection{Reliability of the Constructs}

The reliability of the variables for engagement were already measured by Buchanan and Bryman (2007), therefore validities were already proven. For this study please refer to Table 3 for results:

Table 3 shows the results of reliability analysis and items retained after conducting the reliability analysis tests. The reliability of employee engagement is at the highest i.e. $\alpha=.81(\mathrm{M}=4.75$, $\mathrm{SD}=0.87)$, while the reliability for leadership style is at the lowest i.e. $\alpha=.60(\mathrm{M}=4.79, \mathrm{SD}=1.06)$. Results show that all of the Cronbachs Alpha values of the constructs were found greater than 0.6 which lies under the acceptable range of Cronbachs Alpha values, which shows that items within the constructs have internal consistency as Leech and Onwuegbuzie (2008) suggests these values. 
Table 4.1: Profile of Respondents

\begin{tabular}{|c|c|c|c|}
\hline Variable & & Number & Percentage \\
\hline \multirow[t]{2}{*}{ Gender } & Male & 245 & 64 \\
\hline & Female & 138 & 36 \\
\hline \multirow[t]{4}{*}{ Age } & $21-30$ yrs & 168 & 44 \\
\hline & $31-40$ yrs & 128 & 33 \\
\hline & $41-50$ yrs & 69 & 18 \\
\hline & Greater than 50 yrs & 18 & 5 \\
\hline \multirow[t]{4}{*}{ Income } & Till 20K & 40 & 11 \\
\hline & $21 \mathrm{~K}-30 \mathrm{~K}$ & 130 & 34 \\
\hline & $31 \mathrm{~K}-40 \mathrm{~K}$ & 170 & 44 \\
\hline & $41 \mathrm{~K} \&$ above & 43 & 11 \\
\hline \multirow[t]{2}{*}{ Marital Status } & Single & 234 & 61 \\
\hline & Married & 149 & 39 \\
\hline \multirow[t]{5}{*}{ Education } & 10 Yrs (Matric) & 58 & 15 \\
\hline & 12 Yrs (Inter) & 178 & 47 \\
\hline & 16 Yrs (Grad) & 105 & 27 \\
\hline & 18 Yrs (Post Grad) & 38 & 9 \\
\hline & 22 Yrs (PhD) & 4 & 1 \\
\hline
\end{tabular}

Table 4.2: Descriptive Analysis

\begin{tabular}{lcccc}
\hline & Mean & Std. Dev. & Skewness & Kurtosis \\
\hline Job Fit & 4.6396 & 1.29006 & -.613 & -.089 \\
Affective Commitment & 4.8004 & .94463 & -.402 & -.125 \\
Psychological climate & 4.9060 & .85622 & -.556 & .087 \\
Leadership Style & 4.7998 & 1.06652 & -.270 & -.940 \\
Employee engagement & 4.7571 & .87389 & -.676 &.- .568 \\
\hline
\end{tabular}

\subsection{Exploratory Factor Analysis (EFA)}

Exploratory factor analysis is used to determine the relationships with the constructs. It classifies the underlying associations among measured variables. CFA is not used as to construct the model it only uses the factor loading not ignore cross loading. 
Table 4.3: Reliability of the Constructs

\begin{tabular}{lccccc}
\hline Constructs & Cronbach's Alpha & $\begin{array}{c}\text { Cronbach's Alpha } \\
\text { on Standardized } \\
\text { item. }\end{array}$ & No. of items & Mean Std. Dev. & \\
\hline Job Fit & 0.78 & 0.78 & 5 & 4.63 & 1.29 \\
Affective Commitment & 0.68 & 0.68 & 6 & 4.80 & .94 \\
Psychological climate & 0.67 & 0.67 & 5 & 4.90 & .85 \\
Leadership Style & 0.61 & 0.66 & 5 & 4.79 & 1.06 \\
Employee engagement & 0.81 & 0.81 & 14 & 4.75 & .87 \\
\hline
\end{tabular}

Please refer to table 4 for the obtained results.

Table 4.4: EFA for the Constructs

\begin{tabular}{lccccc}
\hline Constructs & $\begin{array}{c}\text { OriginalKMO } \\
\text { Items }\end{array}$ & $\begin{array}{c}\text { Bartlette's Test of } \\
\text { Sphericity }\end{array}$ & $\begin{array}{c}\text { Item } \\
\text { Re- } \\
\text { tained }\end{array}$ & $\begin{array}{c}\text { Cumulative Factor } \\
\text { Loading }\end{array}$ \\
\hline Job Fit & 5 & 0.78 & 966 & 5 & $70 \%$ \\
Affective Commitment & 6 & 0.68 & 447 & 5 & $64 \%$ \\
Psychological climate & 5 & 0.67 & 236 & 5 & $65 \%$ \\
Leadership Style & 5 & 0.60 & 157 & 4 & $72 \%$ \\
Employee engagement & 10 & 0.81 & 602 & 7 & $67 \%$ \\
\hline
\end{tabular}

The Kaiser-Meyer-Olkin (KMO) is used to examine whether the variable have linear relationships or not. Hair et al. (2006) suggests that the acceptable value for KMO is greater than 0.6. The Bartletts Test of Sphericity for all the constructs was found to be significant at $\mathrm{P}<.05$.

\subsection{Correlation Analysis}

To examine the connection among the variables and find out the effect of multicollinearity, it is necessary to pass the test of correlation (Lund, 2012). Bell and Bryman (2007) suggested that the value of correlation coefficient must exist between $0.20-0.90$. Please refer to Table 5 for correlation results.

\subsection{Construct Validity}

Construct validity is important to determine whether the used variables are applicable to given context or not Fowler Jr and Cosenza (2009). 
Table 4.5: Summarized Correlation Results

\begin{tabular}{lccccc}
\hline Constructs & EE & JF & AC & PC & LS \\
\hline Employee engagement & 1.00 & & & & \\
Job Fit & 0.68 & 1.00 & & & \\
Affective Commitment & 0.57 & 0.70 & 1.00 & & \\
Psychological Climate & 0.51 & 0.45 & 0.51 & 1.00 & \\
Leadership Style & 0.42 & 0.31 & 0.41 & 0.40 & 1.00 \\
\hline
\end{tabular}

Table 4.6: Discriminant Validity

\begin{tabular}{lccccc}
\hline & EE & JF & AC & PC & LS \\
\hline Employee engagement & 0.82 & & & & \\
Job Fit & 0.47 & 0.84 & & & \\
Affective Commitment & 0.32 & 0.50 & 0.80 & & \\
Psychological Climate & 0.26 & 0.20 & 0.26 & 0.81 & \\
Leadership Style & 0.18 & 0.17 & 0.17 & 0.16 & 0.85 \\
\hline
\end{tabular}

\subsection{Overall Model Regression Test}

Table 11 shows the overall model of regression analysis. The summarized results are presented in Table 11 below:

Table 4.7: Regression Results for Overall Model

\begin{tabular}{|c|c|c|c|c|c|c|}
\hline \multirow[b]{2}{*}{ Model } & & \multicolumn{2}{|c|}{ Unstandardized Coefficients } & \multicolumn{3}{|c|}{ Standardized Coefficients } \\
\hline & & B & Std. Error & Beta & $\mathrm{T}$ & Sig. \\
\hline \multirow[t]{5}{*}{1} & (Constant) & 0.471 & 0.301 & & 1.565 & 0.119 \\
\hline & JF_T & 0.431 & 0.048 & 0.521 & 9.034 & 0 \\
\hline & $\mathrm{AC}_{-} \mathrm{T}$ & 0.039 & 0.069 & 0.034 & 0.558 & 0.577 \\
\hline & PC_T & 0.235 & 0.061 & 0.189 & 3.84 & 0 \\
\hline & LS_T & 0.208 & 0.056 & 0.171 & 3.716 & 0 \\
\hline
\end{tabular}

The regression results shows that the overall model indicates that the predictors Job fit, Psychological climate, and Leadership style are significant as $\mathrm{p}<.05$, whereas the predictor affective 
commitment is insignificant.

\section{Discussion and Conclusion}

\subsection{Discussion}

All the four hypotheses failed to be rejected. It was found that job fit was the strongest predictor for the dependent variable employee engagement followed by affective commitment, psychological climate and leadership style. For $\mathrm{H} 1$ related to the positive influence of job fit on employee engagement, the result is consistent to earlier studies i.e. When employees found right degree of job fit in their jobs they are found to be more engaged at the workplace Bakker (2011).

For $\mathrm{H} 2$ related to the influence of affective commitment on employee engagement, the result is consistent to earlier studies i.e. When the employees found support from their colleagues, a strong sense of belonging from organization which results in high level of engagement Cartwright and Holmes (2006).

For $\mathrm{H} 3$ related to the influence of Psychological climate on employee engagement, the result is consistent to earlier studies i.e. when the supervisors are open to suggestions and new ideas, it motivates employees which ultimately results in high level of engagement (Zigarmi, 2008).

For H4 related to the influence of Leadership style on employee engagement, the results are consistent to earlier studies. When immediate supervisor tell their employees about organizations vision and future plans, their role in this regard and opportunities they can get to grow, it ultimately motivates employees and leads to high level of engagement May et al. (2004).

\subsection{Conclusion}

The research present sufficient evidence that the instrument is applicable to local context and culture in contrast to the studies conducted in other context and culture. This specifies that sound multicultural and psychometric measures can be used in assessing the employee engagement. The research also shows relationships amid leadership style, affective commitment, employee engagement, job fit and psychological climate. This consistency suggests that workers in developing and developed countries are relatively similar in reference to the factors that engage these individuals to stay in their organizations. Consequently, it points out to the generalizability of the theories of leadership style, affective commitment, employee engagement, job fit and psychological climate that were developed and tested in Western culture and applied in Pakistani culture.

\subsection{Implication for Managers}

This study can help HR professionals in designing the strategy for turnover retention. The results which are presented in this study can help organizations to identify the potential reasons for engagement which leads to high productivity and profitability. It can also help Managers to engage employees without increasing the budget by just focusing on the organizational climate. Managers are responsible to build the conducive environment of the organization by having a supportive attitude, providing positive feedback, giving empowerment, telling the truth and leading them to future. These actions not only make organizational climate positive but also leads employees to affective commitment. 
This study can help managers in designing a suitable strategy for compensation and benefits. This research breaks some of the myths that high salary engage employees, whereas this study proves that suitable job role, positive climate are related to high level of engagement (Arakawa and Greenberg, 2007; Wagner and Harter, 2007).

\subsection{Limitations and Future Research}

The first limitation of this study was the use of a convenience sample. The samples used in this study are the employees of two pharmaceutical companies operating in the metropolitan city of Pakistan, which is Karachi. The generalizability of the findings are restricted across or other similar industries. There are several limitations with this study, which are as follows:

1. This research study collected data on all measures through self- reported questionnaire. The only source was the employees through which data was collected to test the hypotheses. As a consequence, the observed relationships might be susceptible (Buchanan and Bryman, 2007).

2. Longitudinal data should be established to evaluate the consistency and strength of the relationships being investigated.

3. It is also important to fully understand the influence of national culture on employee engagement to include and assess statistically the relationship between national culture and employee engagement.

\section{References}

Albrecht, S. L. and Marty, A. (2020). Personality, self-efficacy and job resources and their associations with employee engagement, affective commitment and turnover intentions. The International Journal of Human Resource Management, 31(5):657-681.

Allen, N. J. and Meyer, J. P. (1996). Affective, continuance, and normative commitment to the organization: An examination of construct validity. Journal of vocational behavior, 49(3):252-276.

Arakawa, D. and Greenberg, M. (2007). Optimistic managers and their influence on productivity and employee engagement in a technology organisation: Implications for coaching psychologists. International Coaching Psychology Review, 2(1):78-89.

Bakker, A. B. (2011). An evidence-based model of work engagement. Current directions in psychological science, 20(4):265-269.

Barik, S. and Kochar, A. (2017). Antecedents and consequences of employee engagement: A liter- ature review. International Journal of Latest Technology in Engineering, Management \& Applied Science.

Bell, E. and Bryman, A. (2007). The ethics of management research: an exploratory content analysis. British journal of management, 18(1):63-77.

Bernthal, P. and Wellins, R. (2006). Trends in leader development and succession. People and Strategy, 29(2):31.

Breevaart, K., Bakker, A. B., Demerouti, E., and Derks, D. (2016). Who takes the lead? a multisource diary study on leadership, work engagement, and job performance. Journal of Organizational Behavior, 37(3):309-325.

Brown, S. P. and Leigh, T. W. (1996). A new look at psychological climate and its relationship to job involvement, effort, and performance. Journal of applied psychology, 81(4):358.

Buchanan, D. A. and Bryman, A. (2007). Contextualizing methods choice in organizational research. Organizational research methods, 10(3):483-501. 
Buckingham, M. (1999). coffman, c.(1999). First, break all the rules. New York, NY: Simon E Shuster.

Bui, H. T., Zeng, Y., and Higgs, M. (2017). The role of person-job fit in the relationship between transformational leadership and job engagement. Journal of Managerial Psychology.

Busse, R. and Regenberg, S. (2019). Revisiting the authoritarian versus participative leadership style legacy: A new model of the impact of leadership inclusiveness on employee engagement. Journal of Leadership \& Organizational Studies, 26(4):510-525.

Cartwright, S. and Holmes, N. (2006). The meaning of work: The challenge of regaining employee engagement and reducing cynicism. Human resource management review, 16(2):199-208.

Chaudhary, R. and Akhouri, A. (2019). Csr perceptions and employee creativity: examining serial mediation effects of meaningfulness and work engagement. Social Responsibility Journal.

Chen, C.-Y., Yen, C.-H., and Tsai, F. C. (2014). Job crafting and job engagement: The mediating role of person-job fit. International Journal of Hospitality Management, 37:21-28.

Christian, M. S., Garza, A. S., and Slaughter, J. E. (2011). Work engagement: A quantitative review and test of its relations with task and contextual performance. Personnel psychology, 64(1):89-136.

Crabtree, S. (2004). Getting personal in the workplace: Are negative relationships squelching productivity in your company. Gallup Management Journal, 10(1):208.

Czarnowsky, M. (2008). Learnings role in employee engagement: An astd research study. Alexandria, VA: American Society for Training and Development.

Elwyn, L. J., Esaki, N., and Smith, C. A. (2017). Importance of leadership and employee engagement in trauma-informed organizational change at a girls juvenile justice facility. Human Service Organizations: Management, Leadership \& Governance, 41(2):106-118.

Fowler Jr, F. J. and Cosenza, C. (2009). Design and evaluation of survey questions. The SAGE handbook of applied social research methods, pages 375412.
Gebauer, J., Lowman, D., and Gordon, J. (2008). Closing the engagement gap: How great companies unlock employee potential for superior results. Penguin.

Hair, J. F., Black, W. C., Babin, B. J., Anderson, R. E., Tatham, R. L., et al. (2006). Multivariate data analysis (vol. 6).

Harter, J. K., Schmidt, F. L., Asplund, J. W., Killham, E. A., and Agrawal, S. (2010). Causal impact of employee work perceptions on the bottom line of organizations. Perspectives on Psychological Science, 5(4):378-389.

Harter, J. K., Schmidt, F. L., and Keyes, C. L. (2003). Well-being in the workplace and its relationship to business outcomes: A review of the gallup studies.

Huang, Y.-H., Lee, J., McFadden, A. C., Murphy, L. A., Robertson, M. M., Cheung, J. H., and Zohar, D. (2016). Beyond safety outcomes: An investigation of the impact of safety climate on job satisfaction, employee engagement and turnover using social exchange theory as the theoretical framework. Applied ergonomics, 55:248257.

Judge, T. A., Bono, J. E., Ilies, R., and Gerhardt, M. W. (2002). Personality and leadership: a qualitative and quantitative review. Journal of applied psychology, 87(4):765.

Kahn, W. A. (1990). Psychological conditions of personal engagement and disengagement at work. Academy of management journal, 33(4):692724.

Kasemsap, K. (2013). Systematic framework: Constructing a causal model of job fit, affective commitment, employee engagement, and organizational performance. International Journal of Accounting Information Science and Leadership, 6(17):12-23.

Kataria, A., Garg, P., and Rastogi, R. (2019). Do high-performance hr practices augment ocbs? the role of psychological climate and work engagement. International Journal of Productivity and Performance Management. 
Leech, N. L. and Onwuegbuzie, A. J. (2008). Qualitative data analysis: A compendium of techniques and a framework for selection for school psychology research and beyond. School Psychology Quarterly, 23(4):587.

Lockwood, N. R. (2007). Leveraging employee engagement for competitive advantage. Society for Human Resource Management Research Quarterly, 1(1):1-12.

Lund, T. (2012). Combining qualitative and quantitative approaches: Some arguments for mixed methods research. Scandinavian journal of educational research, 56(2):155-165.

Macey, W. H. and Schneider, B. (2008). The meaning of employee engagement. Industrial and organizational Psychology, 1(1):3-30.

Magee, C., Gordon, R., Robinson, L., Caputi, P., and Oades, L. (2017). Workplace bullying and absenteeism: The mediating roles of poor health and work engagement. Human Resource Management Journal, 27(3):319-334.

May, D. R., Gilson, R. L., and Harter, L. M. (2004). The psychological conditions of meaningfulness, safety and availability and the engagement of the human spirit at work. Journal of occupational and organizational psychology, 77(1):11-37.

Meyer, J. P., Allen, N. J., and Gellatly, I. R. (1990). Affective and continuance commitment to the organization: Evaluation of measures and analysis of concurrent and time-lagged relations. Journal of applied psychology, 75(6):710.

O'Neill, B. S. and Arendt, L. A. (2008). Psychological climate and work attitudes: The importance of telling the right story. Journal of Leadership $\mathcal{E}$ Organizational Studies, 14(4):353-370.

Paek, S., Schuckert, M., Kim, T. T., and Lee, G. (2015). Why is hospitality employees psychological capital important? the effects of psychological capital on work engagement and employee morale. International journal of hospitality management, 50:9-26.

Purvanova, R. K., Bono, J. E., and Dzieweczynski, J. (2006). Transformational leadership, job characteristics, and organizational citizenship performance. Human performance, 19(1):1-22.

Raosoft, I. (2004). Sample size calculator. Available from: www. raosoft com/samplesize.

Rhoades, L., Eisenberger, R., and Armeli, S. (2001). Affective commitment to the organization: The contribution of perceived organizational support. Journal of applied psychology, 86(5):825.

Saks, A. M. and Gruman, J. A. (2011). Getting newcomers engaged: The role of socialization tactics. Journal of Managerial Psychology.

Sundaray, B. K. (2011). Employee engagement: a driver of organizational effectiveness. European Journal of Business and Management, 3(8):53-59.

Wagner, R. and Harter, J. K. (2006). 12: The elements of great managing, volume 978 . Simon and Schuster.

Wagner, R. and Harter, J. K. (2007). When theresa freeloader on your team. Harvard Management Update, 12(1):3-5.

Zigarmi, D. (2008). Just leadership: Creating a values-driven community. Leader to Leader, 2008(47):33-38. 